\title{
Papaver nudicaule (Iceland poppy) alleviates lipopolysaccharide-induced inflammation through inactivating NF-KB and STAT3
}

Jae-Hyeon Oh ${ }^{1 \dagger}$, Miyong Yun ${ }^{2,3+}$, Dain Park ${ }^{3,4}$, In Jin Ha ${ }^{4}$, Chang-Kug Kim ${ }^{1}$, Do-Wan Kim', Eun-Ok Kim ${ }^{3 *}$ and Seok-Geun Lee Le, $^{3,45^{*}}$

\begin{abstract}
Background: Papaver nudicaule belongs to the Papaveraceae family, which is planted as an annual herbaceous species generally for ornamental purpose. Papaver rhoeas in the same family has been reported to have various pharmacological activities such as antioxidant and analgesic effects. In contrast, little is known about the pharmacological activity of Papaver nudicaule. In this study, the anti-inflammatory activity of Papaver nudicaule extracts and the action mechanisms were investigated in RAW264.7 macrophage cells.
\end{abstract}

Methods: To investigate the anti-inflammatory activity of five cultivars of Papaver nudicaule with different flower color, samples were collected from their aerial parts at two growth stages (60 and 90 days) and their ethanol extracts were evaluated in the lipopolysaccharide (LPS)-treated RAW264.7 cells by measuring nitric oxide (NO) and prostaglandin E2 (PGE2) levels. Interleukin 1-beta (IL-13), Interleukin-6 (IL-6) and Tumor necrosis factor alpha (TNF-a) production were also analyzed by RT-PCR and multiplex assays. Nuclear Factor-kappa-light-chain-enhancer of activated B cells (NF-KB) and Signal transducer and activator of transcription 3 (STAT3) signaling pathways were examined using western blotting and luciferase reporter assays to reveal the action mechanism of Papaver nudicaule extracts in their anti-inflammatory activity.

Results: All of the Papaver nudicaule extracts were effective in reducing the LPS-induced NO, which is an important inflammatory mediator, and the extract of Papaver nudicaule with white flower collected at 90 days (NW90) was selected for further experiments because of the best effect on reducing the LPS-induced NO as well as no toxicity. NW90 lowered the LPS-induced PGE2 level and decreased the LPS-induced Nitric oxide synthase 2 (NOS2) and Cyclooxygenase 2 (COX2). In addition, NW90 reduced the LPS-induced inflammatory cytokines, IL-1 $\beta$ and IL-6. Furthermore, NW90 inhibited the LPS-induced activation of NF-KB and STAT3.

Conclusions: These results indicate that NW90 may restrain inflammation by inhibiting NF-KB and STAT3, suggesting the potential therapeutic properties of Papaver nudicaule against inflammatory disease.

Keywords: Papaver nudicaule, Inflammation, Macrophage, NF-KB, STAT3

\footnotetext{
* Correspondence: eokim74@gmail.com; seokgeun@khu.ac.kr

† Jae-Hyeon Oh and Miyong Yun contributed equally to this work.

${ }^{3}$ Department of Science in Korean Medicine, Kyung Hee University, Seoul

02447, Republic of Korea

Full list of author information is available at the end of the article
}

(c) The Author(s). 2019 Open Access This article is distributed under the terms of the Creative Commons Attribution 4.0 International License (http://creativecommons.org/licenses/by/4.0/), which permits unrestricted use, distribution, and reproduction in any medium, provided you give appropriate credit to the original author(s) and the source, provide a link to the Creative Commons license, and indicate if changes were made. The Creative Commons Public Domain Dedication waiver (http://creativecommons.org/publicdomain/zero/1.0/) applies to the data made available in this article, unless otherwise stated. 


\section{Background}

Acute inflammation is one of the defensive reactions of biological tissues against external stimuli and is a protective response involving immune cells and molecular mediators. However, hyperinflammatory responses can cause severe sepsis, resulting in multiple organ failure as well as high mortality [1-3]. Therefore, anti-inflammation is an important issue in controlling various diseases. The macrophage plays an important role in the biological defense in the early stage of inflammation by producing inflammatory mediators, including cytokines. Several inflammatory mediators such as NO, PGE2, and cytokines (IL-6, IL-1 $\beta$, and TNF- $\alpha$ ) have been reported to play key roles in the inflammatory response [4]. For this purpose, inhibiting macrophage function inclusive of inflammatory mediators has potential as a therapeutic agent in the treatment of various inflammatory diseases [5-7].

Papaver nudicaule (Iceland poppy, Family: Papaveraceae) is a short-lived perennial plant which has been cultivated mainly for ornamental purpose in many countries including Asia and Europe [8]. As a matter of fact, five cultivars of Papaver nudicaule blooms have been identified (yellow, orange, pink, scarlet and white). The cultivar of white color is the dominant one, while the others are recessive [9]. In Tibet, Europe, and North Asia, the flowers and seeds have been used as mild diaphoretic by folk medicines $[10,11]$ and the leaves have been used as a source of vitamin C [12]. Despite the existence of these folk remedies, their pharmacological activity and action mechanism has not been revealed yet.

In this study, we investigated the inhibitory effects of ethanol extracts of the five cultivars of Papaver nudicaule on the lipopolysaccharide (LPS)-induced inflammation in RAW264.7 cells and its mechanism.

\section{Materials and methods}

\section{Preparation of Papaver nudicaule extracts}

The aerial parts of Papaver nudicaule harvested at two different growth stages (60 and 90 days) were provided by the National Institute of Agricultural Science, Rural Development Administration (Republic of Korea). All five cultivars of Papaver nudicaule with different flower colors were used as noticed in Table 1. Every voucher specimen was identified by Dr. Do-Wan Kim in the

Table 1 Five kinds of Papaver nudicaule with different flower color and the abbreviation

\begin{tabular}{lll}
\hline Species & Color & Abbreviation \\
\hline Papaver nudicaule & White & NW \\
Papaver nudicaule & Orange & NO \\
Papaver nudicaule & Yellow & NY \\
Papaver nudicaule & Scarlet & NS \\
Papaver nudicaule & Pink & NP \\
\hline
\end{tabular}

Genomics Division of the National Institute of Agricultural Science [13]. Here we abbreviate the extract of Papaver nudicaule with white flower harvested at 60 days after seeding to NW60 and the same way for the other extracts (Table 1). The specimens used in this study were deposited in the Genomics Division of the National Institute of Agricultural Science (Republic of Korea). Aerial parts of Papaver nudicaule were lyophilized and then ground into a fine powder. The ethanol extraction methods are previously described [14]. $2 \mathrm{~g}$ of each sample was ultrasonicated for 30 mins with $5 \mathrm{ml}$ of ethanol, and then centrifugation was performed for 15 mins at $13,000 \mathrm{rpm}$ at $4{ }^{\circ} \mathrm{C}$. The supernatants were filtered through the $0.2 \mu \mathrm{m}$ polytetrafluoroethylene syringe filter (Thermo Scientific, Waltham, MA). Each solvent was then evaporated using speed vacuum (Thermo/Savant SPC VAC 2010, Waltham, MA). Each sample extracted was dissolved in DMSO at a concentration of $500 \mathrm{mg} / \mathrm{ml}$ based on the weight of the ground powder after initial lyophilization and stored at $-70{ }^{\circ} \mathrm{C}$ until used in the experiments.

\section{Cell culture and reagents}

RAW264.7 murine macrophage cells were maintained in Dulbecco's modified Eagle's medium (DMEM) containing $10 \%$ FBS and $1 \%$ antibiotic/antimycotic in a humidified incubator with $5 \% \mathrm{CO}_{2}$ at $37^{\circ} \mathrm{C}$. LPS (Escherichia coli serotype 0111: B4) and 3-(4, 5-dimethylthiazol-2-yl)-2, 5-diphenyl-tetrazolium bromide (MTT) were purchased from Sigma-Aldrich (St. Louis, MO, USA). A Nitric oxide detection kit was purchased from iNtRON Biotechnology (Sungnam, Republic of Korea).

\section{Cell viability assays}

Cell viability was measured by MTT assays. Cells $(1 \times$ $10^{4}$ cells/well) were seeded in 96-well plates and incubated overnight. Cells were treated with LPS and Papaver nudicaule extracts for $24 \mathrm{~h} \mathrm{[15],} \mathrm{and} \mathrm{then} 20 \mu \mathrm{l}$ of 2 $\mathrm{mg} / \mathrm{ml}$ MTT solution was added to each well. The cells were incubated at $37^{\circ} \mathrm{C}$ for $3 \mathrm{~h}$. Formazan crystals were dissolved by DMSO and resulting absorbance value was measured using microplate reader (Molecular Devices, California, USA) at $570 \mathrm{~nm}$. Data are presented as mean \pm standard deviation (SD) from at least three independent experiments in triplicate.

\section{Nitric oxide assays}

The nitrite concentration in the culture supernatant was analyzed as an indicator of NO production using Griess reagent. RAW264.7 cells $\left(5 \times 10^{5}\right.$ cells/well $)$ were seeded in 6-well plates and incubated overnight. Cells were pretreated with Papaver nudicaule extracts $1 \mathrm{~h}$ prior to LPS $(100 \mathrm{ng} / \mathrm{ml})$ treatment for $24 \mathrm{~h} \mathrm{[15].} \mathrm{Then} \mathrm{the} \mathrm{cul-}$ ture supernatants were mixed with Griess reagent [equal 
volumes of $1 \%(w / v)$ sulfanilamide in $5 \%(v / v)$ phosphoric acid and $0.1 \%(\mathrm{w} / \mathrm{v})$ naphtylethylenediamine$\mathrm{HCL}$, incubated at room temperature for $10 \mathrm{~min}$, and the absorbance at $540 \mathrm{~nm}$ was measured using a microplate reader. Data are presented as mean \pm SD from at least three independent experiments in triplicate.

\section{Real-time quantitative PCR}

Cells $\left(5 \times 10^{5}\right.$ cells/well $)$ were seeded in 6 -well plates and incubated overnight. Then the cells were pretreated with Papaver nudicaule extracts $1 \mathrm{~h}$ prior to LPS $(100 \mathrm{ng} / \mathrm{ml})$ treatment for $24 \mathrm{~h}$. Total RNA was isolated using TRI Reagent solution (Ambion, Waltham, MA, USA) according to the manufacturer's instructions. Total RNA $(1 \mu \mathrm{g})$ isolated from cells was reverse transcribed to cDNA using PrimeScript first-strand cDNA synthesis kit (Takara Korea Biomedical Inc., Seoul, Republic of Korea) according to the manufacturer's instructions. Amplification of each cDNA was monitored using Sensi FAST SYBR No-ROX kit (Bioline, Taunton, MA, USA) on a StepOnePlus instrument (Waltham, Massachusetts, USA). Specific primers used as following: IL-6 (forward: 5'-CCACGGCCTTCCCTACTTC-3', and reverse: 5' -TTGGGAGTGGTATCCTCTGTGA-3'), TNF- $\alpha$ (forward: $5^{\prime}$-CACCGTCAGCCGATTTGC-3', and reverse: 5'-TTGACGGCAGAGAGGAGGTT-3'), IL-1 $\beta$ (forward: 5'-AGTTGACGGACCCCAAAAGAT-3', and reverse: 5'-GGACAGCCCAGGTCAAAGG-3'), GAPDH (forward: 5'-CAAGGCTGTGGGCAAGGT-3', and reverse: 5'-GGAAGGCCATGCCAGTGA-3'). GAPDH was used as an internal control. Data are presented as mean \pm SD from at least three independent experiments in triplicate.

\section{Western blotting analysis}

Whole cell lysates were prepared and western blotting was performed as described [16]. Cells $\left(3 \times 10^{6}\right.$ cells $)$ were seeded in $100 \mathrm{~mm}$ dishes and incubated overnight. The cells were pre-incubated with Papaver nudicaule extracts for $1 \mathrm{~h}$ and then incubated with LPS $(100 \mathrm{ng} / \mathrm{ml})$ and the extracts for $24 \mathrm{~h}$. Primary antibodies against COX2, NF- $\mathrm{kB}$ p65, phospho-NF- $\mathrm{kB}$ p65, ІкB $\alpha$, phospho-ІкB $\alpha$, STAT3, and phospho-STAT3 were purchased from Cell Signaling Technology (Danvers, MA, USA), NOS2 from Santa Cruz Biotechnology (Santa Cruz, CA, USA), and $\beta$-actin from Sigma-Aldrich. Secondary antibodies HRP-conjugated anti-mouse IgG and anti-rabbit (1:5000-1:10000; Jackson Immuno Research Laboratories, Inc., PA, USA) were used for western blotting. Densitometric analysis of each protein band was calculated using the ImageJ software (https://imagej.nih. gov/ij/). Data are presented as mean $\pm \mathrm{SD}$ from at least three independent experiments.

\section{Multiplex cytokine assays}

Cells $\left(5 \times 10^{5}\right.$ cells/well $)$ were pre-incubated with Papaver nudicaule extracts for $1 \mathrm{~h}$ in 6-well plates, incubated with LPS $(100 \mathrm{ng} / \mathrm{ml})$ and the extracts for $24 \mathrm{~h}$. IL-1 $\beta$, IL-6, and TNF- $\alpha$ were measured using a Magnetic Luminex Assay kit (R\&D Systems, MN, USA) and Luminex 200 array system after collecting the culture medium. Standard curves for each cytokine were generated using the kit-supplied reference cytokines. Data are presented as mean \pm SD from at least three independent experiments in triplicate.

\section{ELISA assays}

Enzyme-linked immunosorbent assay (ELISA) kits were purchased from R\&D system (Minneapolis, MN, USA) for IL-1 $\beta$ and Biochem Inc. (Farmingdale, NY, USA) for PGE2. To measure IL-1 $\beta$ and PGE2 secretion in the culture supernatants, cells $\left(5 \times 10^{5}\right.$ cells/well $)$ were pre-incubated with Papaver nudicaule extracts for $1 \mathrm{~h}$ in 6 well plates and incubated with LPS $(100 \mathrm{ng} / \mathrm{ml})$ and extracts for $24 \mathrm{~h}$. The culture supernatants were collected and the concentration of PGE2 and IL-1 $\beta$ was measured using a microplate reader. Data are presented as mean $\pm \mathrm{SD}$ from at least three independent experiments in triplicate.

\section{Transient transfection and luciferase reporter assays}

NF-kB-Luc and pSTAT3-Luc vectors were previously described [16, 17]. RAW264.7 cells were transiently transfected with NF-kB-Luc or pSTAT3-Luc using Lipofectamine 2000 (Invitrogen, Carlsbad, CA). Transfection efficiency $\quad(>24 \%$ for NF-kB-Luc and $>34 \%$ pSTAT3-Luc) was confirmed by measuring the bioluminescence intensity with flow cytometry (FACS Canto II, BD Biosciences, San Jose, CA) [18]. One day after transfection, the cells were re-plated into 24 well plates $\left(5 \times 10^{4}\right.$ cells/well $)$ and incubated overnight. Then the cells were pre-treated with Papaver nudicaule extracts $1 \mathrm{~h}$ prior to LPS $(100 \mathrm{ng} / \mathrm{ml})$ treatment. Following incubation for 3 or $24 \mathrm{~h}$, luciferase assays were performed using a luciferase assay system (Promega, Madison, WI, USA) according to the manufacturer's instructions. Data are presented as mean \pm SD from at least three independent experiments in triplicate.

\section{Statistical analyses}

Statistical analysis was performed with the SigmaPlot 10.0 software (Systat Software, Inc., San Jose, CA, USA). An unpaired Student's $t$-test was performed between mock and LPS treatment or LPS alone and co-treatment of LPS with Papaver nudicaule extract to calculate the $P$-value [19]. $P<0.05$ was considered significant. 


\section{Results}

\section{Extracts of Papaver nudicaule decrease the LPS-induced} NO and PGE2

In order to investigate the potential anti-inflammatory effect of Papaver nudicaule, we first examined the cytotoxicity of all five cultivars of Papaver nudicaule in RAW264.7 cells. Analysis of cell viability after treatment of each extract did not show any significant cytotoxicity up to $500 \mu \mathrm{g} / \mathrm{ml}$ even though NO90, NY90, and NS90 were slightly cytotoxic at higher concentrations (Fig. 1a). The $\mathrm{IC}_{50}$ values of all five cultivars of Papaver nudicaule extracts were over $2000 \mu \mathrm{g} / \mathrm{ml}$, indicating mild or no toxicity of Papaver nudicaule cultivars we used (Additional file 1: Table S1). To examine the anti-inflammatory effects of Papaver nudicaule extracts, we then evaluated NO production in RAW264.7 cells treated with LPS in the presence or absence of each extract. As shown in Fig. 1b, LPS dramatically increased NO and all of the extracts decreased the LPS-induced NO production. Moreover, their inhibitory effects on NO production were in a dose-dependent manner except NO90 and NS90. In particular, only NW90 noticed that its $\mathrm{IC}_{50}$ value on the inhibitory effect on the LPS-induced NO production was less than $500 \mu \mathrm{g} / \mathrm{ml}$. Based on these results indicating no toxicity and the most effective in decreasing the LPS-induced NO production, NW90, the extract of Papaver nudicaule with white flower harvested at a cultivation period of 90 days, was selected and used for further experiments.

To further verify the effect of NW90 on the LPS-induced inflammatory response, we examined its effect on the expression of PGE2 in RAW264.7 cells. As shown in Fig. 2a, LPS greatly increased PGE2 production and NW90 significantly decreased the LPS-induced PGE2. To understand the molecular mechanism underlying the inhibition of LPS-induced NO and PGE2 production by NW90, we evaluated the expression levels of NOS2 and COX2, which are key enzymes to regulate $\mathrm{NO}$ and PGE2 production, respectively [20-22]. As shown in Fig. 2b-d, NW90 inhibited the LPS-induced expression of NOS2 and COX2. These results indicated that the extract of the Papaver nudicaule cultivar with white flower NW90 decreases the LPS-induced NO and PGE2 by reducing the expression of NOS2 and COX2, respectively.

\section{Extract of NW90 reduces the LPS-induced inflammatory cytokines}

We then analyzed the effect of NW90 on the expression and secretion of inflammatory cytokines such as IL-1 $\beta$, IL-6, and TNF- $\alpha$, which are potent activators of inflammatory responses in macrophage [23]. LPS highly increased mRNA expression and secretion of IL-1 $\beta$, IL-6, and TNF- $\alpha$ (Fig. 3). In contrast, NW90 significantly decreased mRNA expression levels of the LPS-induced IL-1 $\beta$, IL-6, and TNF- $\alpha$ (Fig. 3a). In addition, NW90 reduced the secretion of the LPS-induced IL-1 $\beta$ and IL-6, but no inhibitory effect on the secretion of TNF- $\alpha$ (Fig. 3b). These results suggested that NW90 may have anti-inflammatory effects by reducing the LPS-induced IL-1 $\beta$ and IL-6 production and secretion.

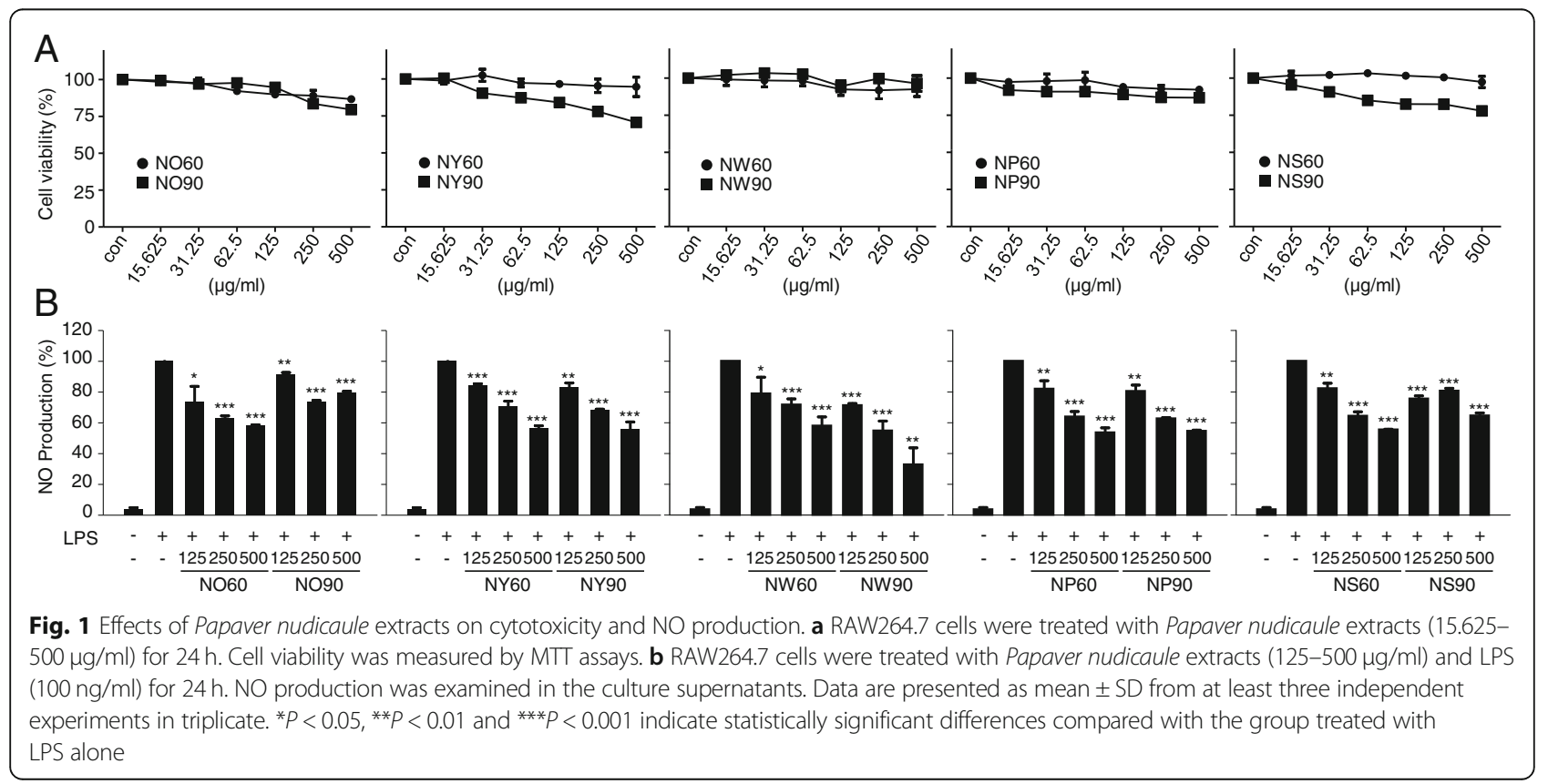



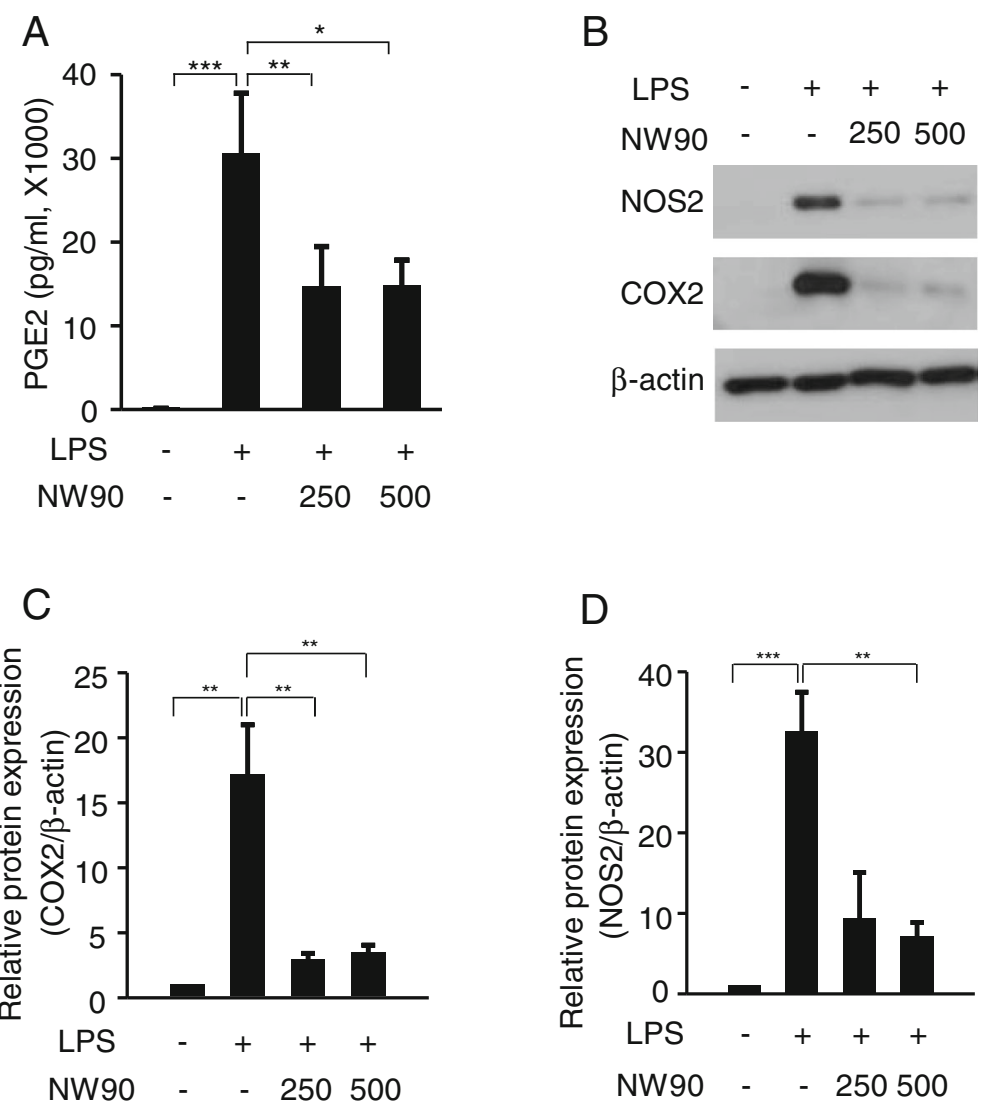

Fig. 2 Effects of Papaver nudicaule extract NW90 on the expression of PGE2, COX2, and NOS2. RAW264.7 cells were treated with NW90 extract $(250$ and $500 \mathrm{\mu g} / \mathrm{ml})$ and LPS $(100 \mathrm{ng} / \mathrm{ml})$ for $24 \mathrm{~h}$. a The PGE2 production was measured in the culture supernatants. b Cells were lysed and the expression of COX2 and NOS2 was examined by western blotting. $\beta$-actin was used as an internal control. c, d Quantification of COX2 and NOS2 expression with normalization to the $\beta$-actin protein levels were analyzed by densitometry analysis of every band using the ImageJ software. Data are presented as mean $\pm S D$ from at least three independent experiments. ${ }^{*} P<0.05,{ }^{* *} P<0.01$ and ${ }^{* *} P<0.001$ indicate statistically significant differences compared with the group treated with LPS alone

\section{Extract of NW90 inhibits the LPS-induced NF-KB and STAT3 activation}

Since transcription factors NF- $\mathrm{kB}$ and STAT3 are known to regulate the expression of inflammatory mediators such as NOS2, COX2 and inflammatory cytokines [24, 25], we next investigated the effect of NW90 on the LPS-induced transcriptional activation of NF-kB and STAT3. As shown in Fig. $4 \mathrm{a}$ and $\mathrm{d}$, LPS induced transcriptional activity of both transcription factors, and NW90 significantly decreased the LPS-induced transcriptional activation of NF-kB and STAT3. Accordingly, NW90 reduced the LPS-induced phosphorylation levels of $\mathrm{I} \kappa \mathrm{B} \alpha, \mathrm{p} 65$ (Fig. 4b and c) and STAT3 (Fig. 4e and f), indicating NW90-mediated inactivation of NF- $\mathrm{kB}$ and STAT3 signaling pathways. These results suggested that NW90 extract is a potent inhibitor of NF- $\mathrm{kB}$ and STAT3.

\section{Discussion}

In this study, the anti-inflammatory activities of Papaver nudicaule against LPS-induced inflammation in RAW264.7 cells were examined. NW90 inhibited the LPS-induced production of NO and PGE2 by regulating the expression of NOS2 and COX2 and also suppressed the LPS-induced production of inflammatory cytokines, IL-1 $\beta$ and IL-6. We further confirmed that NW90 inactivated the LPS-induced NF- $\mathrm{KB}$ and STAT3 activation. These results indicate that Papaver nudicaule is an herbal plant with anti-inflammatory activity through inactivating NF- $\mathrm{KB}$ and STAT3, suggesting a potential to be developed as an anti-inflammatory agent. NF- $\mathrm{kB}$ is a major downstream transcription factor regulating the expression of inflammation-related genes during the induction of inflammatory stimuli such as LPS $[26,27]$ and is also associated with many chronic inflammatory diseases such as inflammatory bowel disease, atopic 


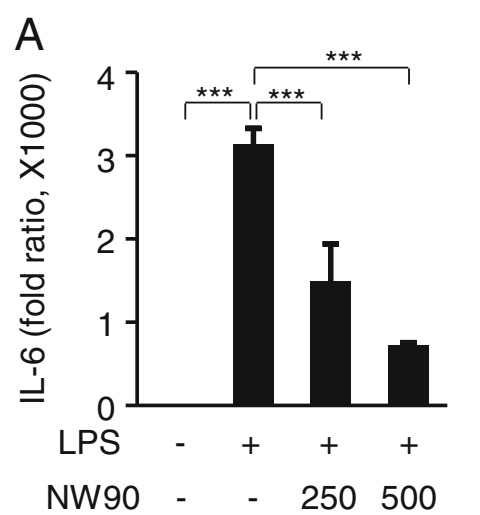

B
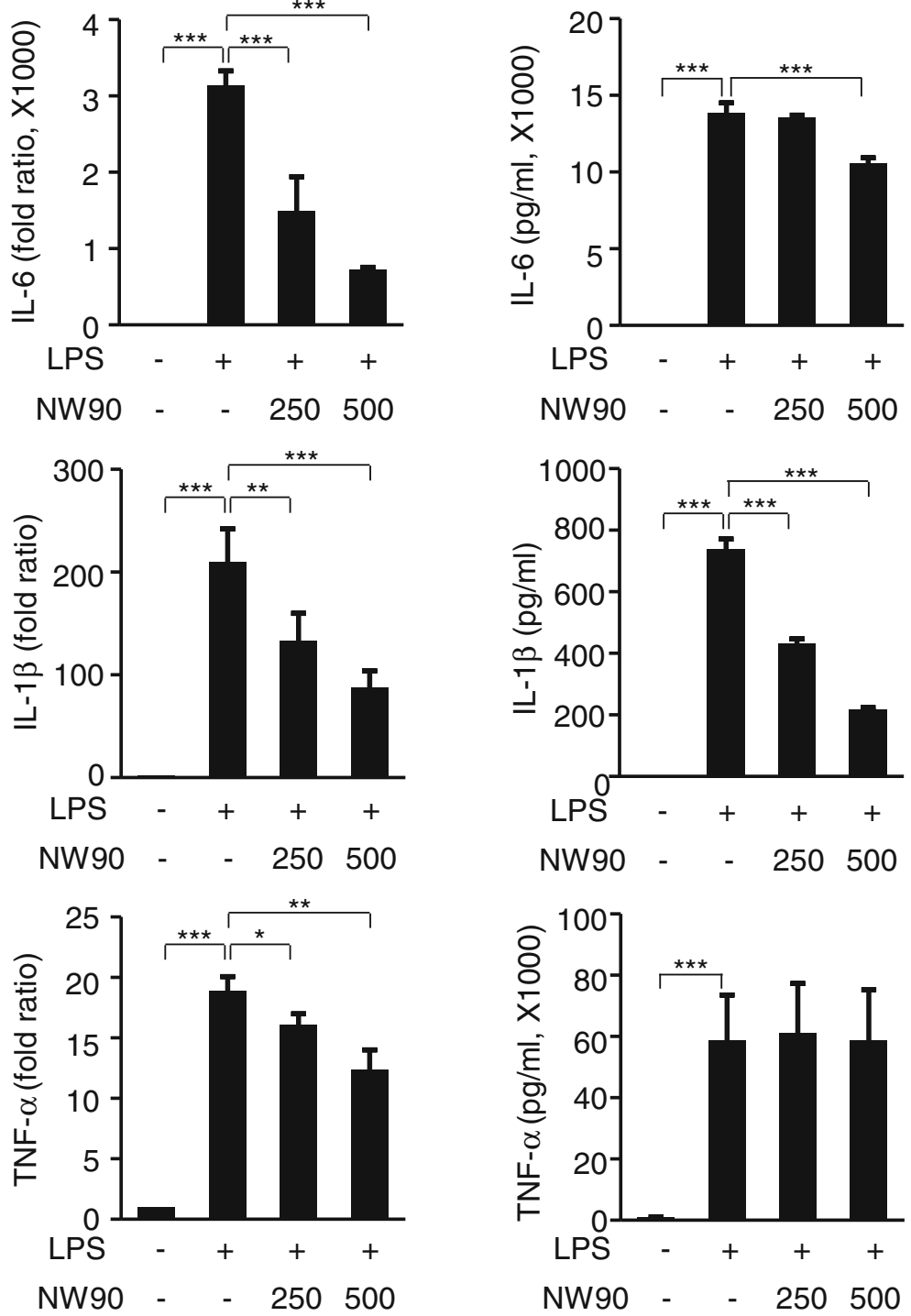

Fig. 3 Effects of Papaver nudicaule extract NW90 on the production of inflammatory cytokines. RAW264.7 cells were treated with NW90 (250 and $500 \mu \mathrm{g} / \mathrm{ml})$ and LPS $(100 \mathrm{ng} / \mathrm{ml})$ for $24 \mathrm{~h}$. a Expression levels of IL-6, IL-1 3 , and TNF-a mRNA were measured by real-time quantitative PCR. GAPDH was used as an internal control. b Secretion levels of $\mathrm{IL}-6, \mathrm{IL}-1 \beta$ and TNF-a were determined by multiplex assays using the culture supernatants. Data are presented as mean \pm SD from at least three independent experiments in triplicate. ${ }^{*} P<0.05$, ${ }^{* *} P<0.01$ and ${ }^{* * *} P<0.001$ indicate statistically significant differences compared with the group treated with LPS alone

dermatitis and rheumatoid arthritis [28]. Therefore, the anti-inflammatory activity of Papaver nudicaule through $\mathrm{NF}-\mathrm{kB}$ regulation is likely to be applied to chronic inflammatory disease. In addition, STAT3 is another important transcription factor involved in the immune response and inflammation and is known to collaborate with NF-kB to control inflammation [27]. Many inflammatory cytokines induced by NF- $\mathrm{KB}$ or STAT3 can positively feedback to activate STAT3 and NF-kB [29]. IL-6 induced by NF- $\kappa$ B activates STAT3, resulting in the increased expression of STAT3-target genes [30]. Therefore, dual inhibition of NF- $\mathrm{kB}$ and STAT3 is an attractive therapeutic strategy for treating inflammatory diseases and we in the present study suggest Papaver nudicaule as a novel candidate for developing a new anti-inflammatory drug targeting both NF- $\mathrm{kB}$ and STAT3.

Studies on the development of anti-inflammatory drug and dietary food using herbal plants as complementary medicine and using phytochemicals have been going for a long time [31]. Various phytochemicals such as flavonoids and alkaloids have been isolated from various plants and their biological activities have been confirmed [32, 33]. Chemical 
A

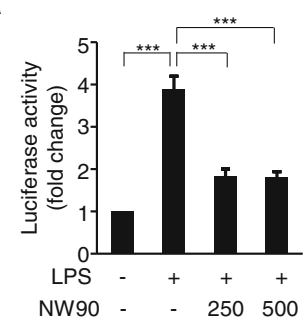

B

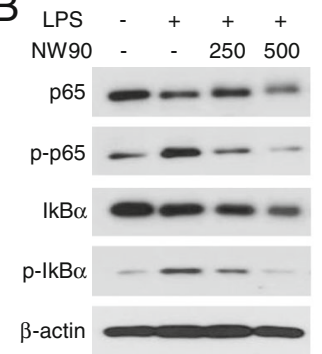

C
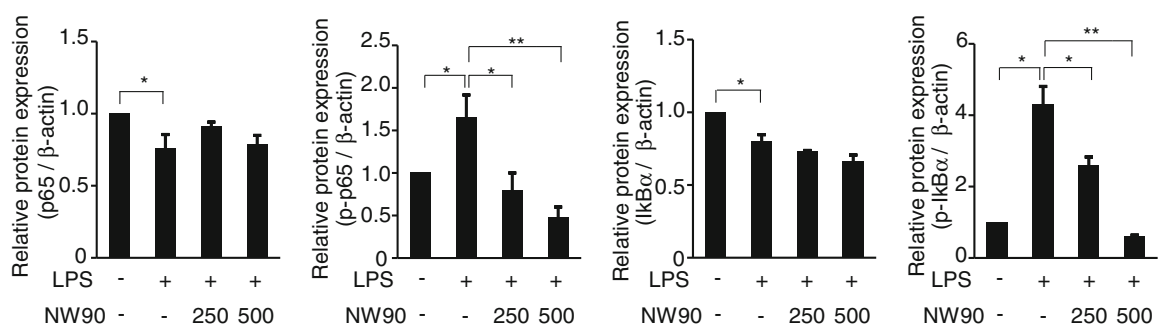

$E$

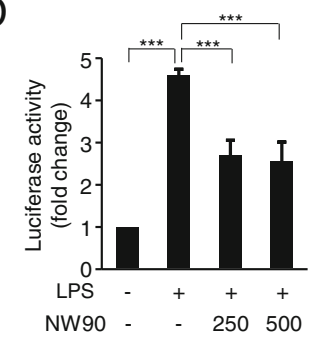

$\mathrm{F}$
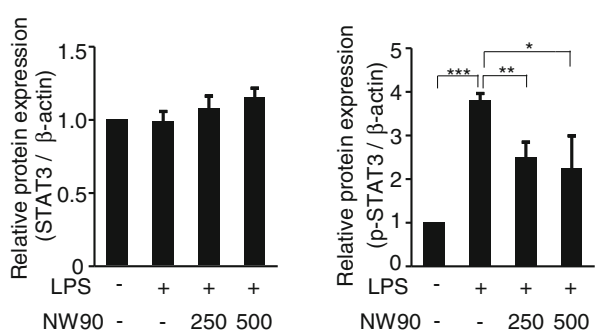

Fig. 4 Effects of Papaver nudicaule extract NW90 on the NF-KB and STAT3 signaling pathways. a, d RAW264.7 cells transfected with the NF-KB-Luc or pSTAT3-Luc were treated with NW90 extract (250 and $500 \mu \mathrm{g} / \mathrm{ml}$ ) and LPS (100 ng/ml). Luciferase activities were measured in cell lysates at 3 (a) or 24 (d) hours after the treatment. Data are presented as mean \pm SD from at least three independent experiments in triplicate. $\mathbf{b}$, e Expression and phosphorylation of p65, IkBa and STAT3 were analyzed by western blotting in the treated RAW264.7 cells as indicated. $\beta$-actin was used as an internal control. c, f Quantification of p65, p-p65, IkBa, p-IkBa, STAT3, and p-STAT3 expression with normalization to the $\beta$-actin protein levels were analyzed by densitometry analysis of every band using the ImageJ software. Data are presented as mean \pm SD from at least three independent experiments. ${ }^{*} P<0.05,{ }^{* *} P<0.01$ and ${ }^{* * *} P<0.001$ indicate statistically significant differences compared with the group treated with LPS alone

compounds and their pharmacological activities of other species in Papaver such as Papaver somniferum and Papaver rhoeas have been characterized well [14, 34]. In contrast, few studies about Papaver nudicaule have been done. Any pharmacological or biological activity of Papaver nudicaule has not been uncovered yet, and just a few alkaloids including chelidonine and allocryptopine have been known in Papaver nudicaule $[18,35,36]$. Although chelidonine is a minor alkaloid in Papaver nudicaule, recent studies indicated that chelidonine extracted from Chelidonium majus suppresses the TNF- $\alpha$ and LPS-induced inflammation by inhibiting NF-kB in HCT 116 and RAW264.7 cells, respectively $[37,38]$. We, thus, analyzed the two known compounds chelidonine and allocryptopine in Papaver nudicaule by LC-MS analysis. Allocryptopine was detected in every extract of all five cultivars of Papaver nudicaule including NW90 (Additional file 2: 
Figure S1). However, chelidonine was not observed in all our samples (data not shown). It is considered that this type of difference is generally caused by various reasons such as usage of another part of the plant (leaf, flower, stem, root, etc.), environmental issues for cultivation, and the cultivation period. We used Papaver nudicaule cultivated in the Republic of Korea, but the other group collected it from Mongolia [18, 36].

In the present study we notice that Papaver nudicaule alleviates the LPS-induced inflammation by suppressing NOS2, COX2 and inflammatory cytokines IL-1 $\beta$ and IL-6 through inhibiting NF-kB and STAT3 pathways, indicating a potential pharmacological activity of Papaver nudicaule for the first time. In contrast to the other Papaver species, Papaver nudicaule has not received any attention in the field of pharmacology or herbal medicine. Beginning our first presentation, further studies about Papaver nudicaule in the context of other pharmacological and biological activities and pharmacochemical analysis will warranty that Papaver nudicaule could be a useful herbal plant for human beings, not just an ornamental poppy.

\section{Conclusion}

Our experimental results indicate that Papaver nudicaule extracts have the anti-inflammatory activity to decrease the inflammatory response induced by LPS through inhibiting NF-kB and STAT3 pathways. Our findings suggest that Papaver nudicaule could be a potentially useful herbal plant with an anti-inflammatory effect.

\section{Additional files}

Additional file 1: Table $\mathrm{S} 1 . \mid \mathrm{C}_{50}$ values of Papaver nudicaule cultivars (DOCX $14 \mathrm{~kb}$ )

Additional file 2: Figure S1. Extracted ion chromatograms of (A) authentic standard of allocryptopine and (B) blank solution and allocryptopine from samples analyzed by LC-QTOF in the ethanol extracts of aerial parts of (C) NW (D) NO (E) NY (F) NS, and (G) NP at a cultivation period of 90 days. Supplementary Methods. The liquid

chromatography-mass spectrometry system consisted of a Thermo Scientific Vanquish UHPLC system (Thermo Fisher Scientific, Sunnyvale, CA, USA) with an Acquity UPLC HSS T3 column $(2.1 \mathrm{~mm} \times 100 \mathrm{~mm}, 1.7 \mu \mathrm{m}$; Waters) and a Triple TOF $5600^{+}$mass spectrometer system (Triple TOF MS; QTOF, Sciex, Foster City, CA, USA). Data acquisition and processing were carried out using Analyst TF 1.7, PeakVeiw 2.2 and MasterView software (Sciex, Foster City, CA, USA). (ZIP $185 \mathrm{~kb}$ )

\section{Abbreviations}

(IL-1ß): Interleukin 1 beta; (IL-6): Interleukin-6; COX2: Cyclooxygenase 2; DMSO: Dimethyl sulfoxide; $I C_{50}$ : Effective concentration required to inhibit half of the maximum biological response (LPS-induced NO production); LPS: Lipopolysaccharide; MTT: 3-(4, 5-dimethylthiazol-2-yl)-2, 5-diphenyltetrazolium bromide; NF-kB: Nuclear Factor-kappa-light-chain-enhancer of activated B; NO: Nitric Oxide; NOS2: Nitric oxide synthase 2; PGE2: Prostaglandin E2; RT-PCR: Reverse transcription polymerase chain reaction; STAT 3: Signal transducer and activator of transcription 3; TNFa: Tumor necrosis factor alpha

\section{Acknowledgments}

There are no special acknowledgments.

\section{Funding}

This study was performed with the support of the National Institute of Agricultural Science (Project no. PJ01184702), Rural Development Administration, Republic of Korea and also supported by the Basic Science Research Program through the National Research Foundation of Korea funded by the Ministry of Education (NRF-2015R1A4A1042399, NRF2016R1D1A1B03932971 and NRF- 2018R1D1A1B07047610). The funding bodies played no role in the design of the study and data collection, analysis, and interpretation of data and in writing the manuscript.

\section{Availability of data and materials}

Data and materials are available from authors on reasonable request.

\section{Authors' contributions}

J-HO, MY, IJH, C-KK, E-OK, and S-GL conceived and designed the experiments. J-HO, MY, DP, E-OK, and S-GL conducted the experiments, analyzed the data, and generated the figures. J-HO, D-WK, and IJH contributed the plant collection and sample preparation. S-GL supervised the whole project, and MY, E-OK and S-GL wrote the manuscript. All authors read and approved the final manuscript.

\section{Ethics approval and consent to participate}

Not applicable

\section{Consent for publication}

Not applicable

\section{Competing interests}

The authors declare that they have no competing interests.

\section{Publisher's Note}

Springer Nature remains neutral with regard to jurisdictional claims in published maps and institutional affiliations.

\section{Author details}

${ }^{1}$ Genomics Division, Department of Agricultural Biotechnology, National Institute of Agricultural Sciences Rural Development Administration, Jellabuk-do 54874, Republic of Korea. ${ }^{2}$ Bioindustry \& Bioresource Engineering, College of Life Sciences, Sejong University, 209 Neungdong-ro, Gwangjin-gu, Seoul 05006, Republic of Korea. ${ }^{3}$ Department of Science in Korean Medicine, Kyung Hee University, Seoul 02447, Republic of Korea. ${ }^{4}$ Korean Medicine Clinical Trial Center, Korean Medicine Hospital, Kyung Hee University, Seoul 02447, Republic of Korea. ${ }^{5} \mathrm{KHU}$-KIST Department of Converging Science \& Technology, and Bionanocomposite Research Center, Kyung Hee University, Seoul 02447, Republic of Korea.

Received: 13 November 2018 Accepted: 8 April 2019

Published online: 29 April 2019

\section{References}

1. Delano MJ, Ward PA. Sepsis-induced immune dysfunction: can immune therapies reduce mortality? J Clin Invest. 2016;126(1):23-31.

2. Bosmann M, Ward PA. The inflammatory response in sepsis. Trends Immunol. 2013;34(3):129-36.

3. Polat G, Ugan RA, Cadirci E, Halici Z. Sepsis and septic shock: current treatment strategies and new approaches. Eurasian J Med. 2017;49(1):53-8.

4. Abdulkhaleq LA, Assi MA, Abdullah R, Zamri-Saad M, Taufiq-Yap YH, Hezmee MNM. The crucial roles of inflammatory mediators in inflammation: a review. Vet World. 2018;11(5):627-35.

5. Guha M, Mackman N. LPS induction of gene expression in human monocytes. Cell Signal. 2001;13(2):85-94.

6. Guzik TJ, Korbut R, Adamek-Guzik T. Nitric oxide and superoxide in inflammation and immune regulation. J Physiol Pharmacol. 2003;54(4):469-87.

7. Nazimek K, Strobel S, Bryniarski P, Kozlowski M, Filipczak-Bryniarska I, Bryniarski $\mathrm{K}$. The role of macrophages in anti-inflammatory activity of antidepressant drugs. Immunobiology. 2017;222(6):823-30.

8. Huang Z, He J, Xia D, Zhong XJ, Li X, Sun LX, Cai SZ. Evaluation of physiological responses and tolerance to low-temperature stress of four 
Iceland poppy (popover nudicaule) varieties. J Plant Interact. 2016;11(1): $117-23$.

9. Fabergé AC. Genetics of the scapiflora section ofPapaver. J Genet. 1942; 44(2-3):169-93.

10. Duke JA. Utilization of Papaver. Econ Bot. 1973;27(4):390-400.

11. Varma; RNCSLNICCLVAKKKOJCBS: Glossary of Indian medicinal plants 1996

12. Hedrick UP. Sturtevant's edible plants of the world: Dover Pubns; 1972

13. Oh J, Shin Y, Ha IJ, Lee MY, Lee SG, Kang BC, Kyeong D, Kim D. Transcriptome profiling of two ornamental and medicinal Papaver herbs. Int J Mol Sci. 2018;19(10):3192.

14. Oh JH, Ha IJ, Lee MY, Kim EO, Park D, Lee JH, Lee SG, Kim DW, Lee $\mathrm{TH}$, Lee EJ, et al. Identification and metabolite profiling of alkaloids in aerial parts of Papaver rhoeas by liquid chromatography coupled with quadrupole time-of-flight tandem mass spectrometry. J Sep Sci. 2018.

15. Koh W, Shin JS, Lee J, Lee $\mathbb{H}$, Lee SK, Ha IH, Chung HJ. Antiinflammatory effect of cortex Eucommiae via modulation of the toll-like receptor 4 pathway in lipopolysaccharide-stimulated RAW 264.7 macrophages. J Ethnopharmacol. 2017;209:255-63.

16. Lim SL, Park SY, Kang S, Park D, Kim SH, Um JY, Jang HJ, Lee JH, Jeong $\mathrm{CH}$, Jang $\mathrm{JH}$, et al. Morusin induces cell death through inactivating STAT3 signaling in prostate cancer cells. Am J Cancer Res. 2015;5(1):289-99.

17. Park SY, Lim SL, Jang HJ, Lee JH, Um JY, Kim SH, Ahn KS, Lee SG. Embelin induces apoptosis in human glioma cells through inactivating NF-kappaB. J Pharmacol Sci. 2013;121(3):192-9.

18. Philipov S, Istatkova R, Yadamsurenghiin GO, Samdan J, Dangaa S. A new 8,14-dihydropromorphinane alkaloid from Papaver nudicaule L. Nat Prod Res. 2007;21(9):852-6.

19. Kang S, Kim EO, Kim SH, Lee JH, Ahn KS, Yun M, Lee SG. Morusin induces apoptosis by regulating expression of Bax and Survivin in human breast cancer cells. Oncol Lett. 2017;13(6):4558-62.

20. Mattila JT, Thomas AC. Nitric oxide synthase: non-canonical expression patterns. Front Immunol. 2014;5:478.

21. Bogdan C. Nitric oxide synthase in innate and adaptive immunity: an update. Trends Immunol. 2015;36(3):161-78.

22. Ricciotti E, FitzGerald GA. Prostaglandins and inflammation. Arterioscler Thromb Vasc Biol. 2011;31(5):986-1000.

23. Arango Duque G, Descoteaux A. Macrophage cytokines: involvement in immunity and infectious diseases. Front Immunol. 2014;5:491.

24. Park MH, Hong JT. Roles of NF-kappaB in Cancer and inflammatory diseases and their therapeutic approaches. Cells. 2016;5(2).

25. Liu T, Zhang L, Joo D, Sun SC. NF-kappaB signaling in inflammation. Signal Transduct Target Ther. 2017;2

26. Lawrence T. The nuclear factor NF-kappaB pathway in inflammation. Cold Spring Harb Perspect Biol. 2009;1 (6):a001651.

27. He G, Karin M. NF-kappaB and STAT3 - key players in liver inflammation and cancer. Cell Res. 2011;21(1):159-68.

28. Pai S, Thomas R. Immune deficiency or hyperactivity-Nf-kappab illuminates autoimmunity. J Autoimmun. 2008:31(3):245-51.

29. Fan Y, Mao R, Yang J. NF-kappaB and STAT3 signaling pathways collaboratively link inflammation to cancer. Protein Cell. 2013;4(3):176-85.

30. Yang J, Liao X, Agarwal MK, Barnes L, Auron PE, Stark GR. Unphosphorylated STAT3 accumulates in response to IL-6 and activates transcription by binding to NFkappaB. Genes Dev. 2007;21(11):1396-408.

31. Azab A, Nassar A, Azab AN. Anti-inflammatory activity of natural products. Molecules. 2016;21(10).

32. Yuan G, Wahlqvist ML, He G, Yang M, Li D. Natural products and antiinflammatory activity. Asia Pac J Clin Nutr. 2006;15(2):143-52.

33. Gautam R, Jachak SM. Recent developments in anti-inflammatory natural products. Med Res Rev. 2009;29(5):767-820.

34. Alagoz Y, Gurkok T, Zhang B, Unver T. Manipulating the biosynthesis of bioactive compound alkaloids for next-generation metabolic engineering in opium poppy using CRISPR-Cas 9 genome editing technology. Sci Rep. 2016;6:30910.

35. Zhang $Y$, Pan $H$, Chen S, Meng $Y$, Kang S. minor alkaloids from the capsule of Papaver nudicaule L. Zhongguo Zhong Yao Za Zhi. 1997; 22(9):550-76.

36. Istatkova R, Philipov S, Yadamsurenghiin GO, Samdan J, Dangaa S. Alkaloids from Papaver nudicaule L. Nat Prod Res. 2008;22(7):607-11.

37. Zhang ZH, Mi C, Wang KS, Wang Z, Li MY, Zuo HX, Xu GH, Li X, Piao $L X, M a J$, et al. Chelidonine inhibits TNF-alpha-induced inflammation by suppressing the NF-kappaB pathways in HCT116 cells. Phytother Res. 2018;32(1):65-75

38. Liao W, He X, Yi Z, Xiang W, Ding Y. Chelidonine suppresses LPS-induced production of inflammatory mediators through the inhibitory of the TLR4/ NF-kappaB signaling pathway in RAW264.7 macrophages. Biomed Pharmacother. 2018;107:1151-9.
Ready to submit your research? Choose BMC and benefit from:

- fast, convenient online submission

- thorough peer review by experienced researchers in your field

- rapid publication on acceptance

- support for research data, including large and complex data types

- gold Open Access which fosters wider collaboration and increased citations

- maximum visibility for your research: over $100 \mathrm{M}$ website views per year

At BMC, research is always in progress.

Learn more biomedcentral.com/submissions 